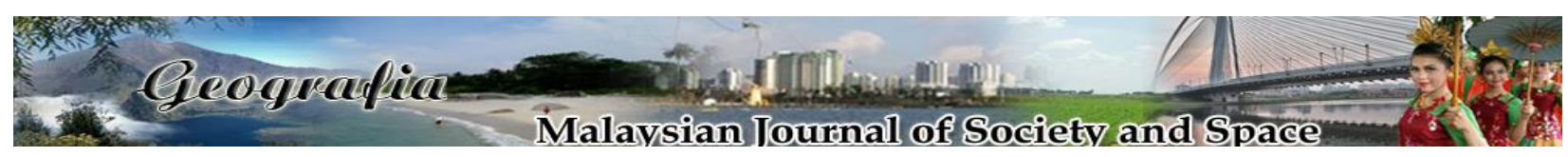

\title{
Tahap keselamatan pejalan kaki untuk perjalanan ke sekolah
}

\author{
Nur Humairah Kamarudin¹, Mazdi Marzuki¹, Rosmiza M.Z.², Jabil Mapjabil \\ 1Jabatan Geografi \& Alam Sekitar, Fakulti Sains Kemanusiaan, Universiti Pendidikan Sultan Idris \\ ${ }^{2}$ Program Geografi, Pusat Kajian Sosial, Pembangunan dan Persekitaran, Fakulti Sains Sosial dan \\ Kemanusiaan, Universiti Kebangsaan Malaysia, \\ ${ }^{3}$ Unit Penyelidikan Etnografi dan Pembangunan, Universiti Malaysia Sabah \\ Correspondence: Mazdi Marzuki (email: mazdi@fsk.upsi.edu.my)
}

Received: 19 May 2020; Accepted: 23 November 2020; Published: 29 November 2020

\begin{abstract}
Abstrak
Kajian ini bertujuan untuk mengkaji tahap keselamatan pejalan kaki dalam kalangan pelajar sekolah menengah. Isu keselamatan sering dibahaskan, namun sehingga kini belum ada formula yang khusus untuk mengatasi masalah ini. Bagi pelajar yang berjalan kaki ke sekolah, mereka lebih terdedah dengan risiko kemalangan jalan raya kerana tidak menghiraukan dan mengabaikan aspek-aspek keselamatan semasa berjalan kaki ke sekolah. Oleh itu, aspek keselamatan harus dipertingkatkan bagi mengurangkan kehilangan nyawa, kecederaan dan kerosakan harta benda yang disebabkan oleh kemalangan yang menimpa pelajar berjalan kaki ke sekolah. Kawasan kajian melibatkan dua buah sekolah terpilih yang terletak di dalam Daerah Sabak Bernam, Selangor. Sekolah Agama Menengah Muhammadiah Pekan Sabak mewakili kawasan bandar dan Sekolah Menengah Kebangsaan Bagan Terap mewakili kawasan luar bandar. Kaedah soal selidik dilakukan ke atas 145 orang sampel melibatkan pelajar sekolah menengah yang berjalan kaki ke sekolah. Data diperoleh menerusi data primer dan sekunder. Data primer diperoleh melalui kaji selidik, pemerhatian dan temu bual. Manakala data sekunder pula diperoleh melalui kajian di perpustakaan, dokumen, laporan dan jurnal. Data dianalisis dengan menggunakan statistik deskriptif yang dipersembahkan dalam bentuk peratusan, kekerapan dan min. Hasil kajian tahap keselamatan pejalan kaki dalam kalangan pelajar menunjukkan kesemua keempat-empat pemboleh ubah iaitu pemboleh ubah tingkah laku pelajar, tingkah laku pengguna jalan raya, kemudahan pejalan kaki dan persekitaran berada pada tahap tidak memuaskan. Beberapa cadangan dikemukakan bagi meningkatkan tahap keselamatan di kalangan pelajar sekolah. Kerjasama daripada pihak kerajaan, sekolah dan masyarakat penting dalam memastikan pejalan kaki dapat melakukan perjalanan yang selamat sewaktu melakukan trip sekolah.
\end{abstract}

Kata kunci: berjalan kaki; bandar; luar bandar; pelajar sekolah; tahap keselamatan 


\title{
The level of pedestrian safety for travelling to school
}

\begin{abstract}
The study aims to examine the level of pedestrian safety among secondary school students. Safety issues are often debated, but up to this date, there is no specific formula to overcome this problem. For students who walk to school, they are more exposed to the risk of road accidents because they neglect and ignore safety aspects while walking to school. Therefore, safety aspects should be improved to reduce the loss of life, injury and property damage caused by accidents that happen to students who are walking to school. The study area involves two selected schools located in the Sabak Bernam district, Selangor. Sekolah Agama Menengah Muhammadiah Pekan Sabak represents the urban area and Sekolah Menengah Kebangsaan Bagan Terap represents the rural area. The questionnaire method was applied on 145 samples involving secondary students who walked to school. Data were obtained through primary and secondary sources. Primary data were obtained through questionnaires, observations, and interviews. While secondary data were obtained through library research, official documents, reports, and journals. The data were analyzed using descriptive statistics presented in the forms of percentage, frequency and mean. The findings of the study on the level of pedestrian safety among the secondary students show that all four variables which are the students' behaviours, road users' behaviours, pedestrian facilities, and the environment are still at the unsatisfactory level. Several suggestions have been proposed to improve the level of safety among school students. Cooperation between the government, schools and communities are important in ensuring that pedestrians can travel safely during school trips.
\end{abstract}

Keywords: pedestrian safety, urban areas, rural areas, school students, safety level.

\section{Pengenalan}

Sekolah merupakan institusi pendidikan formal yang berfungsi untuk menyampaikan ilmu pengetahuan. Sekolah merupakan "rumah kedua" bagi pelajar untuk menuntut ilmu formal dan keadaan ini menyebabkan banyak masa pelajar diluangkan di sekolah. Pelajar harus berulangalik ke sekolah setiap hari dalam proses menuntut ilmu. Setiap manusia melakukan pergerakan seperti ke tempat kerja, pusat membeli belah, sekolah, dan sebagainya. Pelajar merupakan individu yang sentiasa melakukan pergerakan terutamanya sewaktu datang dan pulang daripada sekolah. Pergerakan ini dikenali sebagai trip sekolah (Mazdi, 2012b). Kelancaran perjalanan pelajar sekolah bergantung kepada mod pengangkutan yang digunakan (Ewing, Schieber, \& Zegeer, 2003; Mazdi \& Jamilah, 2006). Pilihan pengangkutan bergantung kepada keperluan individu dengan mengambil kira elemen keselamatan (Ewing et al., 2003; Mazdi, 2012b). Menurut Ros Airien (2007), pelajar yang memilih mod berjalan kaki untuk trip sekolah disebabkan oleh faktor sosioekonomi dan faktor jarak rumah.

Kajian yang dilakukan oleh (Lang, Collins \& Kearns, 2010), menjelaskan bahawa 50 peratus pelajar di sekolah pinggir bandar di Auckland, New Zealand memilih untuk berjalan kaki disebabkan oleh faktor jarak, kekangan masa dan juga keadaan trafik di kawasan sekolah. Tempat tinggal pelajar yang berdekatan dengan sekolah turut mempengaruhi pelajar untuk 
berjalan kaki kerana menjimatkan kos dan masa perjalanan (Ros Airien, 2007; Lang et al., 2010; Mazdi, 2012a). Berdasarkan hasil analisis yang dilakukan oleh Mc Donald (2007), membuktikan elemen masa perjalanan ke sekolah merupakan faktor utama pelajar memilih untuk berjalan kaki ke sekolah. Manakala kajian yang dilakukan oleh Robert dan Nortan (1994), pula membuktikan bahawa faktor sosioekonomi dan pemilikan kenderaan mempengaruhi jumlah pejalan kaki di sekolah Auckland, New Zealand. Jadual 1 menunjukkan faktor pelajar berjalan kaki sebagai trip sekolah.

Jadual 1. Faktor pelajar berjalan kaki sebagai trip sekolah

\begin{tabular}{ll}
\hline \multicolumn{1}{c}{ Faktor } & \multicolumn{1}{c}{ Penyelidik } \\
\hline Jarak & Ros Airien (2007); Lang et al, (2010); Mazdi (2012a). \\
Sosioekonomi & Robert dan Norton (1994); Ros Airien (2007 \\
Masa & Mc Donald (2007); Lang et al, (2010). \\
Menjimatkan kos & Ros Airien (2007); Lang et al, (2010). \\
Pemilikan kenderaan & Robert dan Norton (1994). \\
\hline
\end{tabular}

Menurut Fogarty (2008), pelajar yang melakukan trip sekolah iaitu berulang-alik ke sekolah berkemungkinan diancam bahaya antaranya terlibat dengan kemalangan jalan raya. Pelajar sekolah merupakan sebahagian pengguna yang menggunakan jalan raya sebagai laluan ke sekolah. Trip sekolah merupakan satu trip wajib yang perlu dilakukan oleh pelajar pada setiap hari bersekolah (Mazdi \& Jamilah, 2006). Pengangkutan merupakan elemen yang penting dalam melakukan trip perjalanan. Menurut Shafida Azwina dan Ahmad Farhan (2002), dalam skop pendidikan, mod pengangkutan memainkan peranan yang sangat penting bagi memudahkan perjalanan pelajar ke sekolah. Matlamat utama kajian ini adalah untuk mengkaji tahap keselamatan pelajar yang menggunakan mod berjalan kaki semasa perjalanan sekolah di daerah Sabak Bernam. Antara objektif kajian ialah mengenal pasti jumlah pelajar yang berjalan kaki ke sekolah (i) Mengkaji faktor-faktor yang mempengaruhi pelajar untuk berjalan kaki ke sekolah (ii) Menilai tahap keselamatan pejalan kaki antara sekolah bandar dengan sekolah luar bandar (iii) Mencadangkan langkah-langkah untuk meningkatkan tahap keselamatan pejalan kaki dalam kalangan pelajar sekolah di kawasan bandar dan luar bandar (iv).

\section{Kajian literatur}

\section{Faktor yang mempengaruhi keselamatan pejalan kaki}

Pejalan kaki merupakan golongan ketiga tertinggi yang terlibat dalam kemalangan maut di Malaysia selepas penunggang motosikal dan pemandu kereta (Malaysia, 2011a). Keselamatan pejalan kaki dipengaruhi oleh beberapa faktor dan kebanyakannya berpunca daripada kelajuan kenderaan. Selain itu, tingkah laku juga turut mempengaruhi tahap keselamatan semasa melakukan perjalanan sekolah. Tingkah laku yang tidak selamat antara pemandu kenderaan dan pejalan kaki sewaktu menggunakan jalan raya boleh mendatangkan risiko kemalangan. Ini kerana tingkah laku pemandu dan pejalan kaki saling mempengaruhi antara satu sama lain terutamanya apabila menggunakan jalan raya yang sama. 


\section{Sikap pelajar}

Sikap pejalan kaki yang kurang memberi tumpuan terhadap keadaan trafik sewaktu melintas jalan merupakan punca utama mereka terlibat dalam kemalangan jalan raya (Martin, 2006; Sullman et al., 2011; Heinonen \& Eck, 2007; Zeeger et al., 2009). Menurut Martin (2006), sebanyak 75 peratus kemalangan yang melibatkan pejalan kaki di Australia berpunca daripada kecuaian pejalan kaki itu sendiri sewaktu menggunakan jalan raya. Sikap pelajar sendiri turut menyumbang kepada peningkatan dalam kadar kemalangan jalan raya. Para pelajar yang tidak mematuhi peraturan seperti tidak menggunakan jejantas yang telah disediakan semasa melintas, melintas tanpa menoleh ke kiri dan ke kanan serta berjalan dengan perlahan dan tidak menggunakan lintasan belang turut menyumbang kepada faktor kemalangan. Menurut Adha (2010), faktor utama yang membawa kepada berlakunya kemalangan jalan raya ialah sikap pelajar itu sendiri. Para pelajar yang dikatakan mempunyai sikap yang cuai di jalan raya apabila mereka hilang tumpuan semasa di jalan raya sehingga menyebabkan berlakunya kecederaan.

\section{Pelajar kurang fasih mengenai peraturan jalan raya}

Menurut Adha (2010), pelajar merupakan golongan yang dianggap tidak memiliki ilmu mengenai peraturan jalan raya selengkapnya dalam penggunaan jalan raya seharian. Para pelajar dikatakan kurang fasih mengenai peraturan jalan raya kerana mereka akan melintas jalan raya sesuka hati tanpa menghiraukan kesesakan laluan trafik pada masa berkenaan (Foot, Chapman, \& Wade, 1982). Mereka hanya tahu ingin sampai ke sekolah sebelum sesi persekolahan bermula dan pulang ke rumah sesudah sesi persekolahan tamat. Para pelajar juga mengambil sikap kurang berdisiplin semasa menggunakan jalan raya (Adha, 2010).

\section{Sikap pengguna jalan raya}

Menurut Noor Azilawati (2008), kajian yang dilakukan oleh Polis Diraja Malaysia (PDRM) menunjukkan sikap manusia antara faktor yang dominan penyumbang kepada pertambahan kadar kemalangan jalan raya di Malaysia. Kemalangan di kawasan sekolah seringkali dikaitkan dengan kecuaian pengguna jalan raya yang lain. Menurut Atikullah (2006), kebanyakan pengguna jalan raya seperti pemandu kenderaan kurang prihatin terhadap pelajar yang berjalan kaki ke sekolah. Menurut Carlson, Giuliano, \& Skinner (2002) dan Nik Ibtishamiah et al. (2005), menjelaskan pejalan kaki akan mengalami kesukaran untuk melintas apabila kenderaan tidak mempedulikan kehadiran pejalan kaki di sesuatu kawasan terutamanya pelajar perempuan. Menurut Janette (2010), sikap pemandu yang tidak memberi keutamaan kepada pejalan kaki untuk melintas jalan akan menyumbang sebanyak 27 peratus risiko kemalangan terhadap pejalan kaki. Selain itu, pengguna jalan raya yang mudah terganggu, tertekan, memandu dalam keadaan tidak baik, tidak menghiraukan papan tanda jalan, memintas kenderaan di garisan berkembar, dan membelok tanpa memberi isyarat mempunyai kecenderungan yang tinggi untuk berlakunya kemalangan jalan raya (Lim, 2007). Sikap pemandu yang tergesa-gesa kerana ingin cepat sampai ke destinasi yang dituju turut menyumbang kepada berlakunya kemalangan maut (Wan Muhammad Taufik dan Tarmiji, 2015). 


\section{Kualiti kemudahan pejalan kaki}

Penyediaan kemudahan pejalan kaki yang tidak sempurna turut mempengaruhi pejalan kaki untuk mendapatkan kawasan berjalan yang lebih baik iaitu di sepanjang jalan utama. Antara kemudahan yang diperlukan oleh pejalan kaki adalah laluan pejalan kaki, lintasan pejalan kaki, jejantas, lintasan berlampu isyarat, papan tanda, lampu jalan dan bonggol jalan (Nik Ibtishamiah et al., 2005; Nora, 2007; Chau, 2007; Landis, Vattikuti, Ottenberg, Mcleod, \& Guttenplan, 2007). Kemudahan-kemudahan yang disediakan mempunyai fungsinya yang tersendiri untuk memastikan pejalan kaki dapat melakukan perjalanan dengan selamat.

\section{Persekitaran}

Kemalangan melibatkan pejalan kaki di bandar adalah lebih tinggi berbanding kawasan luar bandar (Ewing et al., 2003; Barton \& Schwebel, 2007b; Papadimitriou et al., 2012; Jehan et al., 2012). Majlis Keselamatan Amerika Syarikat menganggarkan sebanyak 85.7 peratus kemalangan melibatkan pejalan kaki berlaku di kawasan bandar dan sebanyak 14.3 peratus berlaku di kawasan luar bandar. Seramai 4700 orang pejalan kaki meninggal dunia akibat kemalangan jalan raya berpunca daripada rebakan bandar di Amerika Syarikat (Ewing et al., 2003). Jumlah pejalan kaki di kawasan bandar yang lebih tinggi berbanding kawasan luar bandar merupakan faktor utama kawasan bandar lebih berisiko untuk pejalan kaki (Ewing et al., 2003; Mohd Misram, 2008; Jehan et al., 2012).

Tahap keselamatan pejalan kaki di kawasan luar bandar adalah rendah berpunca daripada keadaan jalan raya dan kekurangan kawalan trafik di kawasan lintasan. Kewujudan jalan-jalan yang sempit, terpencil dan banyak simpang di pinggir-pinggir bandar adalah sangat merbahaya kepada pejalan kaki (Ewing et al., 2003; Heinonen \& Eck, 2007; Zeeger et al., 2009). Kemalangan yang berlaku di luar bandar berpunca daripada kelajuan kenderaan di jalan-jalan terpencil yang lengang. Kawalan trafik yang jarang dilaksanakan di kawasan luar bandar atau di jalan-jalan terpencil menyebabkan pemandu berani untuk memandu melebihi had kelajuan yang telah ditetapkan (Heinonen \& Eck, 2007; Zeeger et al., 2009). Keselamatan persekitaran merupakan perkara penting yang perlu dititik beratkan dalam menjamin keselamatan pejalan kaki (Mohd Nasir et al, 2018).

\section{Metod dan kawasan kajian}

Metod kajian yang digunakan adalah pelbagai meliputi penggunaan kaji selidik, temu bual dan pemerhatian di kawasan kajian. Kaji selidik melibatkan 145 orang pelajar sekolah menengah yang berjalan kaki ke sekolah. Pensampelan bertujuan digunakan untuk pemilihan sampel pelajar. Pelajar yang menjadi sampel kajian telah dipilih daripada senarai nama pelajar yang berjalan kaki ke sekolah, Nama pelajar diperoleh daripada guru kaunseling sekolah. Borang kaji selidik diedarkan kepada pelajar melalui guru kaunseling berdasarkan nama yang telah disenaraikan. Kaji selidik ini bertujuan untuk menilai tahap keselamatan pejalan kaki antara sekolah bandar dengan sekolah luar bandar dan cadangan langkah-langkah untuk meningkatkan tahap keselamatan pejalan kaki dalam kalangan pelajar sekolah di kawasan bandar dan luar bandar. Pemerhatian pula melibatkan tinjauan di kawasan kajian tentang kemudahan pejalan kaki yang disediakan di kawasan sekolah di bandar dan luar bandar. Temu bual secara tidak formal 
dilakukan dengan guru sekolah bertujuan untuk mengetahui jumlah pelajar yang menggunakan mod berjalan kaki ke sekolah dan tahap keselamatan pelajar yang menggunakan mod berjalan kaki.

Hasil data yang diperoleh daripada kaedah soal selidik diproses menggunakan ujian statistik melalui perisian Statistical Package for Sosial Science (SPSS) 22.0. Kajian ini menggunakan statistik deskriptif untuk menganalisis dapatan kajian. Analisis deskriptif dilakukan ke atas soalan berskala nominal dan ordinal. Analisis skala nominal menggunakan petunjuk kekerapan dan peratusan dan petunjuk min pula digunakan untuk analisis soalan berskala ordinal.

Kajian ini dilaksanakan di dua buah sekolah yang berbeza, yang mewakili kawasan bandar dan luar bandar. Sekolah yang dipilih ialah Sekolah Agama Menengah Muhammadiah Pekan Sabak dan Sekolah Menengah Kebangsaan Bagan Terap (Rajah 1). SAM Muhammadiah Pekan Sabak dipilih bagi sekolah kawasan bandar yang terletak di daerah Sabak Bernam, Selangor. Kod sekolah bagi SAM Muhammadiah Pekan Sabak ialah BFT6005 dan koordinat sekolah ini bersamaan dengan 3045'44.7' utara dan 101058'35.6' timur. SAM Muhammadiah Pekan Sabak merupakan sekolah yang mempunyai satu sesi pengajian, iaitu sesi pagi sahaja. Jumlah keseluruhan pelajar di SAM Muhammadiah Pekan Sabak pada tahun 2018 adalah seramai 737 orang pelajar.

SMK Bagan Terap terletak di dalam daerah Sabak Bernam Selangor, dipilih sebagai sekolah di kawasan luar bandar. Koordinat sekolah ini terletak pada 3044'55.2', utara dan 101003'21.3' timur manakala kod sekolah ini ialah BEA6044. SMK Bagan Terap merupakan sekolah yang mempunyai satu sesi pengajian, iaitu sesi pagi sahaja. Jumlah keseluruhan pelajar di SMK Bagan Terap pada tahun 2018 adalah seramai 856 orang pelajar. Kajian ini melibatkan dua buah sekolah yang kedua-dua buah sekolah ini berada dalam satu daerah yang sama iaitu daerah Sabak Bernam. Pemilihan dua buah sekolah dari kawasan yang berbeza ini adalah bertujuan untuk melihat tahap keselamatan bagi pelajar yang menggunakan mod berjalan kaki semasa perjalanan sekolah bagi kawasan bandar dan kawasan luar bandar. Pemilihan sampel sekolah ini dilakukan berdasarkan kriteria sekolah perlu berada di kawasan yang dikehendaki iaitu bandar dan luar bandar, mempunyai pelajar yang berjalan kaki dan mendapat kelulusan dari pentadbir untuk dilakukan kajian.

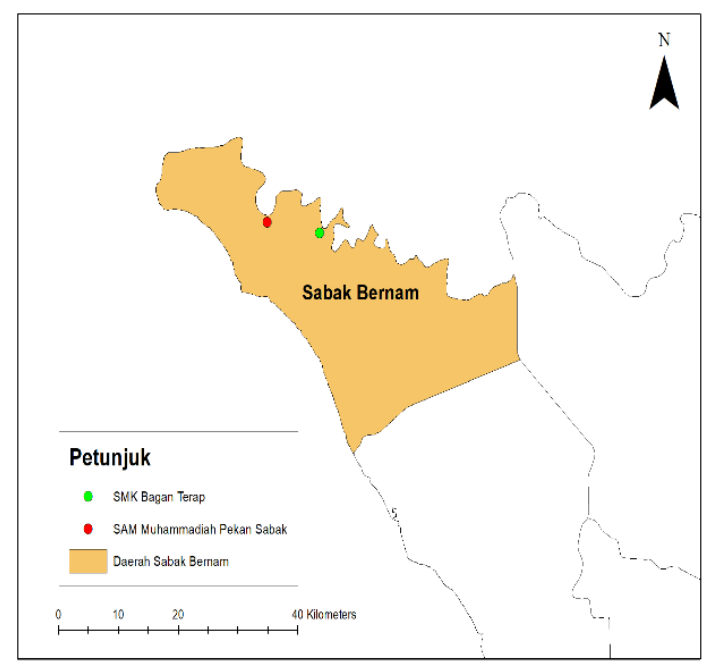

Rajah 1. Sekolah Agama Menengah Muhammadiah Pekan Sabak dan Sekolah Menengah Kebangsaan Bagan Terap. 


\section{Hasil kajian dan perbincangan}

Perbandingan tahap keselamatan pejalan kaki dalam kalangan pelajar sekolah bagi kawasan bandar dan luar bandar

a. Tingkah laku pejalan kaki sewaktu melakukan trip ke sekolah

Hasil kajian yang diperoleh secara keseluruhannya menunjukkan tingkah laku yang tidak selamat sewaktu melakukan trip sekolah adalah sama bagi kedua-dua kawasan. Antara tingkah laku yang tidak selamat adalah suka berbual dengan kawan sewaktu melintas jalan, berjalan beriringan bersama rakan, berjalan secara berkumpulan, jarang menggunakan kemudahan pejalan kaki dan melihat kiri dan kanan jalan sebelum melintas jalan. Tingkah laku ini dikenali sebagai jaywalking iaitu merujuk kepada satu tingkah laku haram atau merbahaya sewaktu menggunakan jalan raya (Heinonen et al., 2007; Zeeger et al., 2009, Sullman et al., 2011). Tingkah laku yang paling tidak selamat adalah keputusan berjalan beriringan bersama rakan iaitu sebanyak 31 orang (34.8 peratus) bagi sekolah bandar dan sebanyak 30 orang (53.6 peratus) bagi sekolah luar bandar (Jadual 2). Hasil pemerhatian di kedua-dua kawasan menunjukkan responden yang berjalan secara berkumpulan dan beriringan seringkali melintas jalan sambil bergurau, makan dan berbual-bual dengan rakan sebelah.

\section{b. Tingkah laku pengguna jalan raya yang lain}

Hasil kajian yang diperoleh daripada sekolah yang terletak di kawasan luar bandar dan bandar menunjukkan faktor kenderaan yang dipandu laju merupakan punca utama responden mengalami kesukaran untuk melintas jalan dengan mencatatkan nilai peratusan sebanyak 51.8 peratus (29 orang) di kawasan luar bandar dan sebanyak 66.3 peratus (59 orang) di kawasan bandar (Jadual 1.3). Heinonen dan Eck (2007) dan Ewing et al. (2003) menjelaskan kenderaan yang dipandu laju bukan hanya memberi kesukaran kepada pejalan kaki untuk melintas jalan malah turut memberi risiko kemalangan jalan raya kerana kenderaan yang dipandu laju gagal dikawal jika menyedari kehadiran pejalan kaki secara mengejut.

Hasil kajian juga mendapati, sikap pengguna jalan raya yang lain yang tidak memberikan laluan semasa responden melintas jalan menunjukkan nilai peratusan yang tinggi di kawasan luar bandar iaitu sebanyak 64.3 peratus (36 orang) berbandingan dengan kawasan bandar sebanyak 43.8 peratus (39 orang). Kajian yang dijalankan oleh Janette (2010), menyatakan sikap pemandu yang tidak memberi keutamaan kepada pejalan kaki untuk melintas jalan akan menyumbang sebanyak 27 peratus risiko kemalangan terhadap pejalan kaki. Sikap pemandu yang tergesa-gesa kerana ingin cepat sampai ke destinasi yang dituju turut menyumbang kepada berlakunya kemalangan maut (Wan Muhammad Taufik \& Tarmiji, 2015). Sikap pemandu yang melanggar peraturan dan tidak menghormati hak-hak laluan pejalan kaki akan memberi risiko keselamatan kepada pejalan kaki (Heinonen \& Eck, 2007; Jehan et al., 2012). 
Jadual 2. Tingkah laku pelajar sewaktu melakukan trip ke sekolah

\begin{tabular}{|c|c|c|c|c|c|c|c|c|}
\hline \multirow[t]{2}{*}{ Elemen Tingkah Laku Pejalan Kaki } & \multicolumn{4}{|c|}{ Sekolah di Kawasan Luar Bandar } & \multicolumn{4}{|c|}{ Sekolah di Kawasan Bandar } \\
\hline & $1(\%)$ & $2(\%)$ & $3(\%)$ & $4(\%)$ & $1(\%)$ & $2(\%)$ & $3(\%)$ & $4(\%)$ \\
\hline Berjalan beriringan bersama rakan & $30(53.6)$ & $15(26.8)$ & $7(12.5)$ & $4(7.1)$ & $31(34.8)$ & $41(46.1)$ & $7(7.9)$ & $10(11.2)$ \\
\hline Berjalan secara berkumpulan & $24(42.8)$ & $16(28.6)$ & $13(23.2)$ & $3(5.4)$ & $26(29.2)$ & $32(36.0)$ & $20(22.5)$ & $11(12.3)$ \\
\hline Menggunakan laluan pejalan kaki & $6(10.7)$ & $12(21.4)$ & $17(30.4)$ & $21(37.5)$ & $27(30.3)$ & $6(6.7)$ & $36(40.4)$ & $20(22.5)$ \\
\hline Melihat kiri dan kanan jalan sebelum melintas jalan & $19(33.9)$ & $11(19.6)$ & $17(30.4)$ & $9(16.1)$ & $14(15.7)$ & $14(15.7)$ & $32(36.0)$ & $29(32.6)$ \\
\hline Menggunakan lintasan belang semasa melintas jalan & $21(37.5)$ & $11(19.6)$ & $15(26.8)$ & $9(16.1)$ & $10(11.2)$ & $16(18.0)$ & $25(28.1)$ & $38(42.7)$ \\
\hline Menggunakan jejantas semasa melintas jalan & $6(10.7)$ & $7(12.5)$ & $21(37.5)$ & $22(24.7)$ & $24(27.0)$ & $16(18.0)$ & $20(22.5)$ & $27(30.3)$ \\
\hline Bergurau bersama rakan sewaktu melintas jalan & $21(37.5)$ & $16(28.6)$ & $9(16.1)$ & $10(17.8)$ & $22(24.7)$ & $22(24.7)$ & $24(27.0)$ & $21(23.6)$ \\
\hline Merancang masa perjalanan ke sekolah & $18(32.1)$ & $15(26.8)$ & $14(25.0)$ & $9(16.1)$ & $35(39.3)$ & $36(40.4)$ & $13(14.6)$ & $5(5.6)$ \\
\hline Mematuhi peraturan pejalan kaki & $12(21.4)$ & $11(19.6)$ & $13(14.6)$ & $20(35.7)$ & $17(19.1)$ & $20(22.5)$ & $25(28.1)$ & $27(30.3)$ \\
\hline
\end{tabular}

1=Kerap, 2=Kadang-Kadang, 3=Jarang, 4=Tidak Pernah

Jadual 3. Tingkah laku pengguna jalan raya yang lain

\begin{tabular}{|c|c|c|c|c|c|c|c|c|c|c|}
\hline \multirow{2}{*}{$\begin{array}{l}\text { Elemen Tingkah Laku Pengguna Jalan } \\
\text { Raya yang Lain }\end{array}$} & \multicolumn{4}{|c|}{ Sekolah di Kawasan Luar Bandar } & \multirow[b]{2}{*}{$5(\%)$} & \multicolumn{5}{|c|}{ Sekolah di Kawasan Bandar } \\
\hline & $1(\%)$ & $2(\%)$ & $3(\%)$ & $4(\%)$ & & $1(\%)$ & $2(\%)$ & $3(\%)$ & $4(\%)$ & $5(\%)$ \\
\hline $\begin{array}{l}\text { Pengguna jalan raya memandu secara } \\
\text { berbahaya di kawasan sekolah }\end{array}$ & $0(0.0)$ & $5(8.9)$ & $16(28.6)$ & $29(51.8)$ & $16(10.7)$ & $0(0.0)$ & $0(0.0)$ & $8(9.0)$ & $59(66.3)$ & $22(24.7)$ \\
\hline $\begin{array}{l}\text { Pengguna jalan raya memandu secara laju di } \\
\text { kawasan sekolah }\end{array}$ & $1(1.8)$ & $8(14.3)$ & $18(32.1)$ & $20(35.7)$ & $9(16.1)$ & $0(0.0)$ & $6(6.7)$ & $17(19.1)$ & $44(29.4)$ & $22(24.7)$ \\
\hline $\begin{array}{l}\text { Pengguna jalan raya memberikan laluan } \\
\text { semasa melintas jalan }\end{array}$ & $1(1.8)$ & $4(7.1)$ & $8(14.3)$ & $36(64.3)$ & $7(12.5)$ & $5(5.6)$ & $1(1.1)$ & $23(25.8)$ & $39(43.8)$ & $21(23.6)$ \\
\hline $\begin{array}{l}\text { Pengguna jalan raya tidak menghiraukan } \\
\text { pelajar semasa sedang melintas }\end{array}$ & $1(1.8)$ & $15(26.8)$ & $27(48.2)$ & 8 (14.2) & $5(8.9)$ & $1(1.1)$ & $6(6.7)$ & $24(27.0)$ & $41(46.1)$ & $17(19.1)$ \\
\hline $\begin{array}{l}\text { Pengguna jalan raya mematuhi peraturan had } \\
\text { laju yang ditetapkan }\end{array}$ & $1(1.8)$ & $5(8.9)$ & $26(46.2)$ & $23(41.1)$ & $1(1.8)$ & $0(0.0)$ & $7(7.9)$ & $24(27.0)$ & $36(40.4)$ & $22(24.7)$ \\
\hline $\begin{array}{l}\text { Pengguna jalan raya memandu sambil } \\
\text { menggunakan telefon bimbit }\end{array}$ & $2(3.6)$ & $15(26.8)$ & $28(50.0)$ & $10(17.8)$ & $1(1.8)$ & $6(6.7)$ & $8(9.0)$ & $22(24.7)$ & 38 (42.7) & $15(16.9)$ \\
\hline
\end{tabular}

1=Sangat Tidak Setuju, 2=Tidak Setuju, 3=Kurang Setuju, 4=Setuju, 5=Sangat Setuju 


\section{c. Persekitaran}

Hasil kajian menunjukkan bahawa pejalan kaki sukar untuk melintas jalan kerana kesesakan jalan raya yang berlaku pada waktu puncak. Bagi kawasan luar bandar kesesakan jalan raya yang berlaku pada waktu puncak mencatat nilai peratusan sebanyak 67.9 peratus (38 orang) berbanding dengan nilai peratusan di kawasan bandar sebanyak 55.1 peratus (49 orang) (Jadual 4). Dapatan kajian ini sependapat dengan Rao, Hawkin dan Gttyer (1997) dan Museru et al. (2003), yang menjelaskan pada waktu puncak, keadaan trafik mula sesak dengan kehadiran kenderaan ibu bapa yang menghantar dan menjemput anak mereka pulang daripada sekolah dan orang dewasa yang pulang dari tempat kerja. Dapatan ini juga selari dengan kajian yang dijalankan oleh Hotz et al. (2004), yang membuktikan kehadiran jumlah kenderaan yang tinggi pada satu ruangan yang terhad memberi risiko keselamatan kepada pejalan kaki. Hasil kajian ini juga disokong oleh kajian Peden et al. (2008); Museru et al. (2003); Nakkito et al. (2008) dan Mohd Nasir et al., (2018), yang menyatakan keadaan lalu lintas yang sibuk menyukarkan pejalan kaki untuk melintas jalan kerana tidak dapat menganggar kelajuan kenderaan dan gagal menentukan jarak kenderaan yang selamat untuk melintas jalan.

Hasil kajian juga membuktikan bahawa elemen struktur jalan raya sepanjang laluan ke sekolah turut mempengaruhi tahap keselamatan pelajar yang berjalan kaki ke sekolah. Kawasan luar bandar mencatat nilai peratusan sebanyak 64.3 peratus (36 orang) yang menyatakan struktur jalan raya sepanjang laluan ke sekolah mempengaruhi tahap keselamatan pelajar berbanding dengan kawasan bandar yang mencatat nilai peratusan 41.6 peratus (37 orang). Ini dikuatkan lagi dengan kajian yang dijalankan oleh Zeeger et al. (2009) dan Janette (2010), yang menyatakan keadaan jalan raya yang lebar dan bersimpang menyukarkan pejalan kaki untuk melintas jalan kerana perlu berhadapan dengan jarak dan jejari untuk membelok yang luas, keadaan lorong yang berganda dan kawalan trafik yang mengelirukan.

\section{d. Kemudahan pejalan kaki}

Hasil kajian mendapati, tahap kemudahan pejalan kaki di kawasan luar bandar dan kawasan bandar berada pada tahap kurang memuaskan. Bagi kawasan bandar, nilai peratusan tahap kepuasan responden terhadap kemudahan lintasan belang (zebra crossing) di kawasan sekolah berada dalam keadaan kurang memuaskan iaitu sebanyak 46.1 peratus (41 orang) berbanding dengan kawasan luar bandar yang mencatat nilai peratusan sebanyak 66.1 peratus (37 orang), lebih tinggi berbanding dengan kawasan bandar. Senario ini berbeza dengan kawasan bandar sebanyak 20 peratus sahaja (Jadual 5). 
Jadual 4. Faktor persekitaran

\begin{tabular}{|c|c|c|c|c|c|c|c|c|c|c|}
\hline \multirow[t]{2}{*}{ Elemen Persekitaran } & \multicolumn{4}{|c|}{ Sekolah di Kawasan Luar Bandar } & \multicolumn{6}{|c|}{ Sekolah di Kawasan Bandar } \\
\hline & $1(\%)$ & $2(\%)$ & $3(\%)$ & $4(\%)$ & $5(\%)$ & $1(\%)$ & $2(\%)$ & $3(\%)$ & $4(\%)$ & $5(\%)$ \\
\hline $\begin{array}{l}\text { Lokasi sekolah yang terletak berhampiran } \\
\text { dengan jalan raya yang sibuk }\end{array}$ & $2(3.6)$ & $1(1.8)$ & $16(28.6)$ & $33(58.9)$ & $4(7.1)$ & $0(0.0)$ & $5(5.6)$ & $5(5.6)$ & $35(39.3)$ & $44(49.4)$ \\
\hline $\begin{array}{l}\text { Kesesakan jalan raya menganggu perjalanan } \\
\text { pelajar ke sekolah }\end{array}$ & $0(0.0)$ & $1(1.8)$ & $7(12.5)$ & $38(67.9)$ & $10(17.8)$ & $2(2.2)$ & $12(13.5)$ & $5(5.6)$ & $49(55.1)$ & $21(23.6)$ \\
\hline $\begin{array}{l}\text { Letakan lokasi sekolah sesuai untuk para } \\
\text { pelajar berjalan kaki ke sekolah }\end{array}$ & $3(5.3)$ & $5(8.9)$ & $22(39.3)$ & $21(37.5)$ & $5(8.9)$ & $2(2.2)$ & $22(24.7)$ & $39(43.8)$ & $23(25.8)$ & $3(3.4)$ \\
\hline $\begin{array}{l}\text { Lokasi sekolah berdekatan dengan rumah } \\
\text { mempengaruhi tahap keselamatan pelajar }\end{array}$ & $0(0.0)$ & $0(0.0)$ & $13(23.2)$ & $34(60.7)$ & $9(16.1)$ & $0(0.0)$ & $2(2.2)$ & $29(32.6)$ & $49(55.0)$ & $9(10.1)$ \\
\hline $\begin{array}{l}\text { Struktur jalan raya sepanjang laluan ke } \\
\text { sekolah mempengaruhi keselamatan pelajar }\end{array}$ & $0(0.0)$ & $1(1.8)$ & $14(25.0)$ & $36(64.3)$ & $5(8.9)$ & $1(1.1)$ & $5(5.6)$ & $30(33.7)$ & $37(41.6)$ & $16(18.0)$ \\
\hline $\begin{array}{l}\text { Pelajar berasa selamat berjalan kaki ke } \\
\text { sekolah }\end{array}$ & $3(5.3)$ & $5(8.9)$ & $28(50.0)$ & $18(32.1)$ & $2(3.6)$ & $4(4.5)$ & $23(25.8)$ & $35(39.3)$ & $25(28.1)$ & $2(2.2)$ \\
\hline Keselamatan pelajar terjamin setiap hari & $2(3.6)$ & $13(23.2)$ & $22(29.2)$ & $18(32.1)$ & $1(1.8)$ & $9(10.1)$ & $26(29.2)$ & $31(34.8)$ & $20(22.5)$ & $3(3.4)$ \\
\hline
\end{tabular}

Nota: $1=$ Sangat Tidak Setuju, 2=Tidak Setuju, 3=Kurang Setuju, 4=Setuju, 5=Sangat Setuju

Jadual 5. Kemudahan pejalan kaki di sekitar kawasan sekolah

\begin{tabular}{|c|c|c|c|c|c|c|c|c|c|c|}
\hline \multirow[t]{2}{*}{ Elemen Kemudahan Pejalan Kaki } & \multicolumn{4}{|c|}{ Sekolah di Kawasan Luar Bandar } & \multirow[b]{2}{*}{$5(\%)$} & \multirow[b]{2}{*}{$1(\%)$} & \multicolumn{4}{|c|}{ Sekolah di Kawasan Bandar } \\
\hline & $1(\%)$ & $2(\%)$ & $3(\%)$ & $4(\%)$ & & & $2(\%)$ & $3(\%)$ & $4(\%)$ & $5(\%)$ \\
\hline $\begin{array}{l}\text { Kemudahan pejalan kaki di sekolah } \\
\text { mencukupi }\end{array}$ & $3(5.3)$ & $8(14.3)$ & $28(50.0)$ & $15(26.8)$ & $2(3.6)$ & $3(3.4)$ & $19(21.3)$ & $57(64.0)$ & $6(6.7)$ & $4(4.5)$ \\
\hline $\begin{array}{l}\text { Kemudahan pejalan kaki di sekolah berada } \\
\text { dalam keadaan baik }\end{array}$ & $0(0.0)$ & $4(7.1)$ & $33(58.9)$ & $7(12.5)$ & $12(21.4)$ & $0(0.0)$ & $34(38.2)$ & $49(55.0)$ & $3(3.4)$ & $3(3.4)$ \\
\hline $\begin{array}{l}\text { Kemudahan pejalan kaki yang disediakan di } \\
\text { sekolah menjamin keselamatan }\end{array}$ & $0(0.0)$ & $5(8.9)$ & $31(55.3)$ & $19(33.9)$ & $1(1.8)$ & $0(0.0)$ & $41(46.1)$ & $39(43.8)$ & $9(10.1)$ & $0(0.0)$ \\
\hline $\begin{array}{l}\text { Keselesaan semasa menggunakan kemudahan } \\
\text { pejalan kaki di sekolah }\end{array}$ & $0(0.0)$ & $7(12.5)$ & $29(51.8)$ & $19(33.9)$ & $1(1.8)$ & $0(0.0)$ & $31(34.8)$ & $51(57.3)$ & $3(3.4)$ & $4(4.5)$ \\
\hline $\begin{array}{l}\text { Laluan pejalan kaki di sekolah berada dalam } \\
\text { keadaan baik }\end{array}$ & $0(0.0)$ & $3(5.3)$ & $30(53.6)$ & $15(26.8)$ & $8(14.3)$ & $0(0.0)$ & $32(35.9)$ & $43(48.3)$ & $14(15.7)$ & $0(0.0)$ \\
\hline $\begin{array}{l}\text { Lintasan belang di kawasan sekolah berada } \\
\text { dalam keadaan baik }\end{array}$ & $0(0.0)$ & $3(5.3)$ & $37(66.1)$ & $11(19.6)$ & $5(8.9)$ & $8(9.0)$ & $20(22.5)$ & $41(46.1)$ & $22(24.7)$ & $2(2.2)$ \\
\hline $\begin{array}{l}\text { Kemudahan papan tanda di kawasan sekolah } \\
\text { menjamin keselamatan }\end{array}$ & $0(0.0)$ & $2(3.6)$ & $4(7.1)$ & $37(66.1)$ & $13(23.2)$ & $6(6.7)$ & $10(11.2)$ & $23(25.8)$ & $44(49.4)$ & $6(6.7)$ \\
\hline
\end{tabular}

Nota: 1=Sangat Tidak Setuju, 2=Tidak Setuju, 3=Kurang Setuju, 4=Setuju, 5=Sangat Setuju 
Hasil pemerhatian di SMK Bagan Terap dan SAM Muhammadiah Pekan Sabak menunjukkan warna lintasan belang sedikit pudar. Dapatan kajian ini selari dengan kajian yang dijalankan oleh Karst dan Rufo, (2011) dan Hilimia (2007), yang menyatakan bahawa keadaan warna lintasan belang yang sedikit pudar disebabkan oleh geseran roda kenderaan dengan jalan raya, menyebabkan segelintir pelajar tidak menyedari kewujudan kemudahan tersebut. Hasil kajian juga menunjukkan perbezaan tahap kepuasan responden terhadap kemudahan lintasan belang. Menurut Mohd Misram (2008), lintasan belang tidak sesuai disediakan di kawasan yang mempunyai kadar trafik kenderaan yang tinggi dan aliran pejalan kaki yang berterusan serta kawasan yang beroperasi di bawah kawalan trafik bandar. Kawasan yang mempunyai isipadu pejalan kaki kurang daripada 50 orang dengan isipadu lalu lintas kurang daripada 100 buah kenderaan pada waktu puncak memerlukan kemudahan lintasan belang sebagai alat untuk melintas jalan dengan selamat (http://www.mpn.gov.my/html).

Hasil kajian juga membuktikan, tahap kepuasan responden terhadap kemudahan pejalan kaki di kawasan sekolah berada dalam keadaan baik kurang memuaskan di kawasan luar bandar dan bandar. Bagi kawasan luar bandar, nilai peratusan menunjukkan bahawa sebanyak 58.9 peratus (33 orang) responden kurang setuju dengan kenyataan kemudahan pejalan kaki di kawasan sekolah berada dalam keadaan baik. Bagi kawasan bandar pula sebanyak 55 peratus (49 orang) responden kurang setuju dengan kenyataan tersebut. Berdasarkan hasil pemerhatian yang dijalankan di kawasan kajian menunjukkan kemudahan pejalan kaki di sekitar kawasan sekolah tidak di selenggara dengan baik. Kemudahan pejalan kaki yang kurang diselenggara terutamanya di kawasan sekolah memberi risiko keselamatan kepada para pelajar yang berjalan kaki untuk trip sekolah.

\section{Cadangan polisi-polisi yang sesuai untuk meningkatkan tahap keselamatan pelajar berjalan kaki ke sekolah}

Elemen cadangan ini dibahagikan kepada empat bahagian yang merangkumi elemen pendidikan, kempen, autoriti undang-undang, dan kemudahan pejalan kaki.

\section{Pendidikan}

Hasil kajian menunjukkan pendidikan keselamatan wajar dilaksanakan di peringkat sekolah menunjukkan min purata sebanyak 4.16 iaitu bersetuju. Responden bersetuju pendidikan keselamatan wajar di sekolah supaya pelajar dapat pendedahan awal berkenaan dengan keselamatan jalan raya khususnya bgi pelajar yang menggunakan mod berjalan kaki ke sekolah. Responden mencadangkan penerapan nilai pendidikan jalan raya yang diterapkan dalam kurikulum agar pendidikan keselamatan jalan raya yang digarapkan lebih bersifat holistik. Hasil kajian menunjukkan sebanyak 4.00 nilai min hasil analisis skala min dan berada pada skala bersetuju. Nilai pendidikan jalan raya penting bagi memastikan para pelajar mempunyai ilmu keselamatan khususnya pelajar yang berjalan kaki ke sekolah agar pelajar selamat sampai dan pulang daripada sekolah. 
Jadual 6. Cadangan elemen pendidikan

\begin{tabular}{|c|c|c|c|c|c|c|}
\hline Kriteria Pendidikan & 1 & 2 & 3 & 4 & 5 & Min \\
\hline $\begin{array}{l}\text { Wajarkah pendidikan keselamatan pelajar berjalan kaki ke sekolah } \\
\text { dilaksanakan di peringkat sekolah }\end{array}$ & 4 & 4 & 10 & 74 & 53 & 4.16 \\
\hline $\begin{array}{l}\text { Wajarkah KPM mengkaji semula kurikulum bersepadu untuk } \\
\text { menerapkan kurikulum pendidikan keselamatan }\end{array}$ & 3 & 5 & 19 & 80 & 38 & 4.00 \\
\hline $\begin{array}{l}\text { Melaksanakan program keselamatan berjalan kaki di peringkat } \\
\text { sekolah }\end{array}$ & 2 & 0 & 17 & 74 & 52 & 4.20 \\
\hline
\end{tabular}

\section{Kempen}

Berdasarkan jadual 7, hasil kajian menunjukkan kempen yang akan digunakan untuk meningkatkan tahap keselamatan pejalan kaki ke sekolah menunjukkan min bersetuju dengan kenyataan tersebut. Responden bersetuju dengan pendapat dan cadangan untuk mengedarkan risalah mengenai keselamatan jalan raya kepada sekolah-sekolah di kawasan bandar dan kawasan luar bandar dengan nilai min sebanyak 4.22. Pengedaran risalah ini adalah bertujuan untuk memastikan para pelajar mempunyai pengetahuan mengenai tahap keselamatan berjalan kaki ke sekolah serta dapat mewujudkan persekitaran melintas yang selamat terhadap pelajar sekolah.

Jadual 7. Cadangan elemen kempen

\begin{tabular}{lllllll}
\hline Kriteria Kempen & $\mathbf{1}$ & $\mathbf{2}$ & $\mathbf{3}$ & $\mathbf{4}$ & $\mathbf{5}$ & Min \\
\hline $\begin{array}{l}\text { Mengedarkan risalah mengenai keselamatan jalan raya kepada } \\
\text { sekolah-sekolah di bandar dan luar bandar }\end{array}$ & 2 & 5 & 10 & 70 & 58 & 4.22 \\
\hline
\end{tabular}

1=Sangat Tidak Setuju, 2=Tidak Setuju, 3=Kurang Setuju, 4=Setuju, 5=Sangat Setuju

\section{Autoriti undang-undang}

Hasil kajian menunjukkan responden bersetuju dengan cadangan penguatkuasaan undangundang agar kadar pematuhan jalan raya menjadi lebih berkesan dengan nilai min sebanyak 4.44 (Jadual 8). Responden juga menunjukkan min (4.15) iaitu bersetuju dengan cadangan meminda undang-undang keselamatan jalan raya yang sedia ada khusus kepada pelajar sekolah. Selain itu, bagi memastikan tahap keselamatan pelajar yang berjalan kaki ke sekolah berada pada tahap selamat, cadangan supaya pihak berwajib membuat pemantauan semasa pelajar datang dan pulang dari sekolah menunjukkan min kurang bersetuju iaitu sebanyak 3.98 menghampiri nilai min setuju.

Jadual 8. Cadangan elemen autoriti undang-undang

\begin{tabular}{|c|c|c|c|c|c|c|}
\hline Kriteria Autoriti Undang-Undang & 1 & 2 & 3 & 4 & 5 & Min \\
\hline $\begin{array}{l}\text { Penguatkuasaan undang-undang agar kadar pematuhan jalan raya } \\
\text { lebih berkesan }\end{array}$ & 1 & 1 & 7 & 60 & 76 & 4.44 \\
\hline $\begin{array}{l}\text { Meminda undang-undang keselamatan jalan raya yang sedia ada } \\
\text { khusus kepada pelajar sekolah }\end{array}$ & 2 & 2 & 21 & 67 & 53 & 4.15 \\
\hline $\begin{array}{l}\text { Pihak berwajib membuat pemantauan semasa pelajar datang dan } \\
\text { pulang dari sekolah }\end{array}$ & 11 & 1 & 17 & 67 & 49 & 3.98 \\
\hline
\end{tabular}




\section{Kemudahan pejalan kaki}

Berdasarkan jadual 9, hasil kajian menunjukkan responden bersetuju dengan cadangan untuk menambahbaik kemudahan pejalan kaki yang sedia ada dengan min sebanyak 4.61. Di samping itu, responden juga bersetuju sekiranya pihak yang bertanggungjawab menyediakan laluan pejalan kaki di kawasan sekolah berkenaan dengan min sebanyak 4.51. Dengan adanya kemudahan-kemudahan pejalan kaki yang baik di kawasan sekolah maka tahap keselamatan dalam kalangan pelajar berjalan kaki ke sekolah akan lebih terjamin.

Jadual 9. Cadangan elemen autoriti undang-undang

\begin{tabular}{lcccccc}
\hline Kriteria Kemudahan Pejalan Kaki & $\mathbf{1}$ & $\mathbf{2}$ & $\mathbf{3}$ & $\mathbf{4}$ & $\mathbf{5}$ & Min \\
\hline Menambahbaik kemudahan pejalan kaki yang disediakan & 1 & 1 & 4 & 42 & 97 & 4.61 \\
Menyediakan laluan pejalan kaki & 2 & 1 & 3 & 54 & 85 & 4.51 \\
\hline 1=Sangat Tidak Setuju, 2=Tidak Setuju, 3=Kurang Setuju, 4=Setuju, 5=Sangat Setuju & & & &
\end{tabular}

\section{Kesimpulan}

Hasil dapatan kajian membuktikan bahawa tahap keselamatan pelajar berjalan kaki ke sekolah kaki bagi kawasan bandar dan kawasan luar bandar masih berada pada tahap yang tidak memuaskan. Penyediaan kemudahan, keadaan persekitaran, aspek tingkah laku pejalan kaki, dan tingkah laku pengguna jalan raya yang lain masih perlu diperbaiki dan dipandang serius oleh semua pihak. Beberapa polisi pengurusan keselamatan pejalan kaki terutamanya di kawasan sekolah perlu dilaksanakan seperti melakukan penyelenggaraan terhadap kemudahan pejalan kaki dan perlaksanaan autoriti undang-undang.

Tambahan itu, beberapa cadangan penambahbaikan turut dibincangkan sebagai usaha mengurangkan risiko kemalangan jalan raya sekaligus dapat meningkatkan tahap keselamatan pelajar yang berjalan kaki sebagai trip pendidikan. Beberapa cadangan untuk kajian masa hadapan juga di kemukakan bagi memperbaiki kelemahan dan kekurangan kajian. Antaranya ialah kajian harus berfokus kepada faktor-faktor yang mempengaruhi pilihan mod untukn berjalan kaki ke sekolah. Kajian sekunder harus diperbanyakkan lagi untuk memperoleh maklumat mengenai faktor-faktor yang mempengaruhi pilihan mod berjalan kaki ke sekolah. Kesukaran untuk memperoleh maklumat daripada kajian lepas merupakan permasalahan yang dihadapi semasa melaksanakan kajian. Selain itu, jumlah responden juga hendaklah ditambah lagi agar skop kajian dapat diperluaskan lagi pada masa hadapan. Sebagai kesimpulannya, usaha penambahbaikan dan perancangan polisi yang lebih efisen dan teratur perlu dilaksanakan dengan penglibatan semua komuniti masyarakat dalam usaha mengurangkan risiko keselamatan pejalan kaki dalam kalangan pelajar sekolah agar negara tidak kehilangan lebih ramai penyambung modal insan pada masa akan datang.

\section{Rujukan}

Adha, G. (2010, Februari 8). Pelajar tidak peduli undang-undang trafik. Berita Harian, Hlm. 6. Atikullah, A. (2006). Tanggani kemalangan jalan raya melalui pendekatan syariat Islam. Kuala Lumpur: Penerbit Pemikir. 
Barton, B.K. \& Schwebel, D.C. (2007b). The roles of age, gender, inhibitory control, and parental supervision in children's pedestrian safety. Journal of Pediatric Psychology, 32(5), 517-526.

Carlson, E.D., Giuliano, G. \& Skinner, R.E. (2002). The relative risks of school trave: A national perspective and gidance for local community risk assessment. (Transportation Research Board Special Report 269). Washington. D.C.

Chau, C.H. (2007). Kajian kesudian berjalan kaki oleh pelajar UKM. Latihan Ilmiah yang tidak diterbitkan. Bangi: Fakulti Kejuruteraan: Universiti Kebangsaan Malaysia (UKM).

Ewing, R., Schieber, R. A., \& Zegeer, C. V. (2003). Urban sprawl as a risk factor in motor vehicle occupant and pedestrian fatalities. American Journal of Public Health, 93(9), 15411545 .

Fogarty, R. (2008). The school as a home for the mind. United Stated of America: Corwin Press.

Foot, A.E., Chapman, A.J., \& Wade, F.M. (1982). Pedestrian accidents. London: John Wiley \& Sons.

Heinonen, J.A. \& Eck, J.E. (2007). Pedestrian injuries and fatalities problem oriented guides for police problem-specific guides series. Guide No. 51. U.S: Department of Justice Office of Community Oriented Policing Services.

Hilmilia. S. (2005). Aspek keselamatan jalan dan kemudahan pejalan kaki di dalam pusat bandar dari perspektif wanita: Kajian kes jalan Tuanku Abdul Rahman, Kuala Lumpur. Latihan Ilmiah yang tidak diterbitkan. Skudai: Universiti Teknologi Malaysia (UTM).

Hotz, GA., Cohn, M., Castelblanco, A., Colston, S., Thomas, M., Weiss, A., Nelson, J., \& Duncan, R. (2004). Walksafe: A school-based pedestrian safety intervention program. Traffic Injury Preview Journal, 5(4), 382-389.

Janette, S.K. (2010). The New York City pedestrian safety study \& action plan. New York: New York City Department of Transportation.

Jehan, M.I., Day, H., Hirshon, J.M., \& El-Setouhy, M. (2012). Road risk-perception and pedestrian injuries among students at Ain Shams University, Cairo, Egypt. Unpublished dissertation. Faculty of Medicine, Ain Shams University. Cairo: Egypt.

Karst, K.P. \& Rufo, M. (2011). Stepping to school: An assessment of neighbourhood walkability and solutions for a safer. Healthier New Orleans. New Orleans: Kids Walk Coalition.

Lang, D., Collins, D., \& Kearns, R. (2010). Understanding modal choice for the trip to school. Transport Geography Journal, 19(4), 509-514.

Landis, B.W., Vattikuti, V.R., Ottenberg, R.W., Mcleod, D.S. \& Guttenplan, M. (2007). Modeling the roadside walking enviroment: A pedestrian level of service. Washington: TRB in Transportation Research.

Lim, A.K. (2007). Hubungan sikap pengguna dengan keterlibatan dalam kemalangan jalan raya: Kajian kes di Negeri Melaka. Pulau Pinang: Universiti Sains Malaysia (USM).

Malaysia. Pedestrian safety facility in Malaysia. (2011a). Kuala Lumpur: Jabatan Kerja Raya Malaysia.

Martin, A. (2006). Factors influencing pedestrian safety: A literature review. Pedestrian attitudes, behavior and road safety client. Landon: Transport for London.

Mazdi, M. \& Jamilah, M. (2006). Mod pengangkutan ke sekolah: satu kajian pilihan pelajar sekolah menengah di Hulu Langat. Proceeding Malaysian Universities Transport Research Forum Conference. Department of Civil and Structural Engineering. National University of Malaysia. 
Mazdi, M. (2012a). Memperkasa perancangan laluan jalan kaki untuk pembangunan lestari kampus: Kajian di Universiti Pendidikan Sultan Idris. In Technology, Science, Social Sciences and Humanities International Conference 2012. Kedah: Universiti Teknologi Mara Kedah.

Mazdi, M. (2012b). Penggunaan pengangkutan dan tahap aksesibiliti pelajar orang asli untuk trip sekolah di Majlis Daerah Tapah. Prosiding seminar antarabangsa ke-5. Ekologi, habitat manusia \& perubahan lingkungan di alam Melayu. Indonesia: Universiti Riau.

Mc Donald, N. (2007). Children's mode choice for the school trip: The role of distance and school location in walking to school. Transportation Journal, 35(1), 23-35.

Mohd Misram, K.A. (2008). Kemudahan-kemudahan dan ciri-ciri pejalan kaki di kawasan bandar. Disertasi yang tidak diterbitkan. Skudai: Universiti Teknologi Malaysia (UTM).

Mohd Nasir, S., Fauziah, I., Salina, N., Norulhuda, S., Nasrudin, S., Azianura Hani, S., Shahrul Nazmi, S. \& Zaizul A. R. (2018). Keselamatan persekitaran perumahan dalam kalangan remaja di kawasan Program Perumahan Rakyat (PPR). Geografia-Malaysian Journal of Society and Space, 14(4), 115-126.

Museru, M.T. Leshabari. \& N.A.A Mbeembati. (2003). Patterns of road traffic injuries and associated factors among school-aged children in Dares Salaam, Tanzania. East and Central African Journal of Surgery, 7(1), 23-26.

Nakkito, M.T., Mutto, M., Howard, A. \& Lett, R. (2008). Pedestrian traffic injuries among school children in Kawempe, Uganda. African Health Sciences Journal, 8(3), 156-159.

Nik Ibtishamiah, I., Mohamed Rehan, K., \& Farhan, A.K. (2005). Motorists and pedestrian interaction at unsignalised pedestrian crossing. Proceedings of the Eastern Asia Society for Transportation Studies, 5, 120125, 2005. Kuala Lumpur: University of Malaya.

Noor Azilawati, M.S. (2008). Kerjasama membendung kemalangan. Petaling Jaya: Pintar Firus Sdn. Bhd.

Nora, M.L. (2007). Audit keselamatan pejalan kaki di Bandaraya Johor Bahru. Latihan Ilmiah tidak diterbitkan. Skudai: Universiti Teknologi Malaysia.

Papadimitriou, E., Yannis, G. \& Golias, J. (2012). Analysis of pedestrian risk exposure in relation to crossing behavior. TRB: Annual Meeting.

Peden. M., Oyegbite. K., Smith. J.O., Hyder. A.A., Branche. C. \& Fazlur, R. (2008). World report on child injury prevention. UNICEF: World Health Organization.

Rao, R., Hawkin, M. \& Gttyer, B. (1997). Children's exposure to traffic and risk of pedestrian injury in an urban setting. Bulletin of The New York Academy of Medicine, 74(1), 65-80.

Robert, I., \& Nortan, R. (1994). Aucland children's exposure to risk as pedestrians. New Zealand.

Ros Airien, I. (2007). Audit keselamatan pejalan kaki dan penunggang basikal di kampus UTM. Universiti Teknologi Mara (UTM).

Shafida Azwina, M. S., \& Ahmad Farhan, M. S. (2002). The comparison of trip generation behaviour between an urban school and a rural school. In Conference Proceedings Malaysian Universities Transport Researh Forum, 22-23 Oktober 2002. Fakulti Kejuruteraan Universiti Malaya.

Sullman, M.J., Gras, M.E., Font-Mayolas, S., Masferrer, L., Cunill, M., \& Planes, M. (2011). The pedestrian behaviour of Spanish adolescents. J Adolesc., 34(3), 531-9.

Wan Muhammad Taufik, W. H. \& Tarmiji, M. (2015). Analisis trend dan pola keruangan kemalangan maut jalan raya di Malaysia: Kajian kes di Daerah Timur Laut, Pulau Pinang. Geografia-Malaysian Journal of Society and Space, 11(13), 104-114. 
Zegeer, C.V., Sandt, L. \& Scully, M. (2009). How to develop a pedestrian safety action plan. Final Report. Federal Highway Administration. U.S: Department of Transportation. 